$11-1-2021$

\title{
Effect of environmental CSR initiatives on potential stakeholders' perception of non-environmentally friendly sporting events
}

\author{
Yong-chae Rhee \\ Washington State University, yong-chae.rhee@wsu.edu \\ Yukyoum Kim \\ Seoul National University, ykim22@snu.ac.kr
}

Follow this and additional works at: https://trace.tennessee.edu/jasm

Part of the Education Commons, Social and Behavioral Sciences Commons, and the Sports Management Commons

\section{Recommended Citation}

Rhee, Yong-chae and Kim, Yukyoum (2021) "Effect of environmental CSR initiatives on potential stakeholders' perception of non-environmentally friendly sporting events," Journal of Applied Sport Management: Vol. 13 : Iss. 1.

https://doi.org/10.7290/jasm133282

Available at: https://trace.tennessee.edu/jasm/vol13/iss1/3

This article is brought to you freely and openly by Volunteer, Open-access, Library-hosted Journals (VOL Journals), published in partnership with The University of Tennessee (UT) University Libraries. This article has been accepted for inclusion in Journal of Applied Sport Management by an authorized editor. For more information, please visit https://trace.tennessee.edu/jasm. 


\title{
Effect of Environmental CSR Initiatives on Potential Stakeholders' Perceptions of Non-Environmentally Friendly Sporting Events
}

\author{
Yong Chae Rhee \\ Yukyoum Kim
}

\begin{abstract}
The protection of the natural environment is increasingly being perceived as a pillar of CSR (corporate social responsibility). Although most professional sport organizations in the United States participate in some form of philanthropic activity, little research has examined how non-environmentally friendly sport organizations can effectively communicate their environmental initiatives. Two different CSR approaches (Environmental and Nationalistic) by NASCAR were exposed to potential stakeholders to examine the changes in the perception (Attitude, Reputation, Identification, and Perceived CSR) of the organization. We analyzed the MIMIC model to compare the means on the latent constructs. Environmental approach showed positive changes in potential stakeholders' perception toward NASCAR. Whereas, the Nationalistic CSR approach had no significant impact on potential stakeholders' perception of the organization. The findings suggest CSR can be an opportunity for organizations like NASCAR to have a positive non-product message for potential stakeholders depending on how they communicate these programs.
\end{abstract}

Keywords: corporate social responsibility, cause related marketing, environmental marketing, nationalistic marketing

\footnotetext{
Yong Chae Rhee is an Associate Professor at Washington State University

Yukyoum Kim is a Professor and Associate Dean at Seoul National University

Please send correspondence to Yong Chae Rhee, yong-chae.rhee@wsu.edu
} 


\section{Introduction}

Little research has examined how non-environmentally friendly sport organizations can effectively communicate their corporate social responsibility (CSR) behaviors even though most professional sport organizations in the United States participate in some form of philanthropic activity and there is a growing body of knowledge about the enhancement of current sustainability efforts in sport (e.g., Babiak \& Trendafilova, 2011; Trail \& Mccullough, 2018). Consider NASCAR's recent CSR efforts, which include both environmental and nationalistic initiatives. NASCAR Green, the environmental initiative, offers an intriguing and insightful case to study and learn about effective CSR communication. Although NASCAR operates the most theoretically unsustainable sport (i.e., burning gasoline, oil, and rubber), the association has adopted a series of initiatives devoted to sustainability in a strategic effort to make their collective image more "green." This includes activities such as using ethanol fuel, planting acres of trees, and implementing a new recycling program.

Along with the more recent environmental initiative, there is a historical nationalistic approach to NASCAR marketing efforts. Historically, NASCAR has aligned themselves with traditional American values: patriotism, hard work, religion, the triumph of good over evil, and competition. To this day, NASCAR continues engaging in a nationalistic approach to CSR (e.g., pledge of allegiance to the American flag, playing the national anthem, a military color guard) to appeal to their fanbase. Bearing that in mind, it should come as little surprise that the promotion of NASCAR Green has been communicated in two distinctly different ways: nationalistic and environmental. Thus, against the backdrop of NASCAR, the purpose of this research was to (a) investigate how potential stakeholders perceive the ways in which sport organizations communicate their CRM for different stakeholder concerns (either nationalistic or environmental) and (b) examine which form of communication, environmental or nationalistic, is more effective for sport organization's cause-related marketing with potential stakeholders.

\section{Review of Literature}

Corporate Social Responsibility and the Green Initiative

Companies attempt to maximize stakeholder returns by utilizing environmental strategies to create a sustainable, competitive advantage (Bonifant, Arnold \& Long, 1995; Miles \& Covin, 2000). However, as green/environmental marketing continues to grow, so does the temptation for companies to "greenwash" their practices. "Greenwashing" occurs when companies attempt to make their business appear more environmentally friendly and socially responsible than they actually are. This type of superficial and opportunistic green marketing can be unpleasant in the eyes of consumers and regulators and can lead to significant consequences (Polonsky \& Rosenberger, 2001).

A consequence of "greenwashing" can be "ethical blowback". "Ethical blowback" refers to stakeholder's negative reactions towards a company's ethical practices or social outcomes of their business operations. This usually takes three forms. The first form centers on companies that engage in questionable activities with no concern for the social consequences of their actions (e.g., tobacco companies), and that are perceived as "all bad." The second form occurs when companies that claim to be socially responsible do not live up to their commitments, as shown by BP's neglect of pipeline erosion after claiming to be "environmentally conscientious". The third form appears when stakeholders think that a company is being hypocritical (e.g., claiming to be socially responsible in one area but not being socially responsible in other areas). Nike, for example, has vowed to erase the stains of racism and injustice in the United States while at the same time employing slave labor in China to make their products (Mosher, 2020).

Sport entities are trying hard to position themselves as socially responsible organizations by engaging in CSR activities (e.g., NFL 60, NBA Cares, MLB Green, etc.). Indeed, entities such as NASCAR, the National Football League (NFL), and National Basketball Association (NBA) are devoting considered time, money, and human capital to engage their fanbase to engage in more sustainably responsible behaviors (Trail \& McCullough, 2018). Even so, there are numerous ways in the ways the sport industry negatively impacts the environment. Sport events, for instance, impact the environment with significant carbon footprints with stadium construction and energy use, player and spectator travel, and media coverage. Therefore, sport organizations need to be cautious in selecting their CSR initiative for the fact that it is possible for potential stakeholders to perceive sport organizations as engaging in negative, insincere practices such as greenwashing (Miller, 2017).

\section{Corporate Social Responsibility and the Nationalistic Initiative}

Many marketing tactics imply that buying behavior has an element of nationalism in it and that certain types of consumption are nationalistic (Stearns, Borna, \& Oakenfull, 2003). After the tragedies of September 11th, Gen- 
eral Motors vowed to "Keep America Running" and made buying a car a nationalistic duty. According to an American Demographics poll, consumers overwhelmingly agreed that "Made in America" mattered to their purchase intentions. Tags declaring "Proudly Made in the USA" have also increased in the past decade (Stearns et al.).

Sport often represents a platform for the expression of patriotism and nationalism (Akhter, 2007). The positive aspects of patriotism in sport include building international relations and appreciation of good play. Professional sport organizations can reinforce links to nationalism through advertising images, rituals, and ceremonies (Adeyanka, 2010). Indeed, sport in the United States often (and expectedly) reflects a distinctly American theme. Because sport is rooted in aspiration for greatness as well as conquest, the presentation of sports in the United States may be unique (Eitzen, 2012). Consider how United States is the only country that plays its national anthem before every game and calls the domestic league winners "world champions." Around the country, ballparks, arenas, and raceways often display gigantic American flags, often the size of the playing field or court, during every event (Eitzen).

\section{RDAP Model at a Glance}

Building upon Carroll (1979) and Wartick and Cochran (1985), Clarkson (1995) evaluated a company's performance of its stakeholder responsibilities through the framework of RDAP (reactive, defensive, accommodative, or proactive) with the added elements of posture or strategy and performance. This framework suggests that the environmental responsiveness of a company can range on a continuum of no response (do nothing) to a proactive response (do more than needed). A range of typologies designed to classify companies in terms of their environmental management practices can be summarized in terms of the reactive, defensive, accommodative, and proactive (RDAP) model.

An organization's commitment to CSR can be assessed by scrutinizing its impact on the issues of concern for stakeholders (Maignan \& Ferrell, 2004). Specifically, this study will analyze how potential stakeholders perceive the level of commitment of NASCAR's CSR through the use of the RDAP model and how that influences their attitudes towards the company. NASCAR's CSR has been communicated through two different cause-related marketing initiatives: environmental (eco-friendly, green initiatives) and nationalistic (American-grown corn, creating American jobs.) This research will also seek to provide insights into the extent to which levels of nationalistic and environmental identification translate into consumer behavior and attitudes towards the different forms of CSR communication.

Hypothesis 1-1: Green initiative will have positive impact on attitude toward NASCAR

Hypothesis 1-2: Green initiative will have positive impact on NASCAR's reputation

Hypothesis 1-3: Green initiative will have positive impact on fan's identification with NASCAR

Hypothesis 1-4: Green initiative will have positive impact on perceived NASCAR's CSR

Hypothesis 2-1: Nationalistic initiative will have positive impact on attitude toward NASCAR

Hypothesis 2-2: Nationalistic initiative will have positive impact on NASCAR's reputation

Hypothesis 2-3: Nationalistic initiative will have positive impact on fan's identification with NASCAR

Hypothesis 2-4: Nationalistic initiative will have positive impact on perceived NASCAR's CSR

\section{Participants and Procedures}

\section{Methods}

The design for this research was an experimental study using a convenience sample of 135 undergraduate students. This experimental research focused on the predictors (communication of CRM initiatives) and outcomes (attitude, fan identification, corporate reputation, and perceived CSR performance) in two separate cause-related marketing initiatives promoted by NASCAR. The total potential population consisted of 266 participants; of that total, 135 participants were 
used for actual analysis. The total sample consisted of $87(64.4 \%)$ males and $48(35.6 \%)$ females. The majority of the participants were 18 to 23 years old (97\%) and Caucasian (White: 76.3\%).

The procedure transpired over a course of two weeks using a pre-test/post-test design. During the first week of the study, participants were asked to take a 15-item questionnaire. One week later, participants were randomly assigned to watch one of two short videos created by NASCAR.

The first video, entitled "American Ethanol and NASCAR: An Introduction," provided the cause-related marketing initiative communicated through nationalism. The first two minutes of the video was shown to participants. The video highlighted the benefits of using a fuel source made in the United States: "every lap will be fueled by Sunoco Green E-15. A fuel that includes $15 \%$ renewable, American ethanol. Which is produced from corn grown and harvested on farms across our country. And made right here in the U.S.A." The video also places interest on American energy independence, the creation of American jobs, and the use of American resources. "It's done here in the U.S., not somewhere else, being imported in.” This dialogue is presented alongside continuous images of the American flag, the United States military, American farmland, and predominantly white American workers and fans.

The second two-minute video, entitled "NASCAR Green: Sustainability and Responsibility," demonstrated NASCAR's cause-related marketing framed as environmentally motivated. The video starts with a clip of a NASCAR race, followed by a scene of the outdoors, and then the "NASCAR Green" logo. The voiceover discusses statistics relating to NASCAR's recycling program, tree-planting program, ethanol fuel, energy efficient buildings, and solar panels. NASCAR, the video claims, wants to "put the environment at the forefront of every aspect of the sport." The only time the word "America" is used is during a clip of then-President Obama honoring NASCAR's commitment to the environment.

\section{Measurement}

To measure the constructs of our study, we modified previously developed scales for our context. The resultant 15-item questionnaire consisted of five main components: (1) perceived CSR of NASCAR, (2) attitudes toward NASCAR, (3) fan identification, (4) corporate reputation of NASCAR, (5) perceived social performance. All items, except for demographics and perceived social performance, were measured using a seven-point Likert-type scale except two items. The Team Identification items (How strongly do you see yourself as a fan of NASCAR? and How strongly do your friends see you as a fan of NASCAR?) could not be accurately responded to using strongly disagree or strongly agree. For those items, we used the anchors extremely (7) to not at all (1).

\section{Measurement Model}

\section{Results}

The model fit the data well $\left(\mathrm{S}-\mathrm{B} \chi^{2} / d f=92.18 / 48=1.92\right.$, CFI $=.94$, SRMR $=.06$, RMSEA $=.08,90 \% \mathrm{CI}^{\mathrm{RMSEA}}[.06, .11]$, WRMR = .98). The factor loadings, AVE, and reliability coefficients of measurement scales are reported in Table 1.

The measurement scales demonstrated good psychometric properties as indicated by all significant factor loadings in the predicted direction $(p<.05)$, AVE values ranging from .56 for Corporate Reputation to .63 for Attitude toward NASCAR and reliability coefficients ranging from .80 for Corporate Reputation to .85 for Perceived CSR. In addition, results provided support for discriminant validity. We examined discriminant validity for each construct by conducting multiple $\chi 2$ difference tests of unity between all pairs of constructs. The unconstrained model (i.e., correlation estimated freely) was significantly better than the constrained model (i.e., correlation between a pair of latent factors constrained as 1) in all comparisons (the smallest adjusted $\Delta \mathrm{S}-\mathrm{B} \chi^{2}$ was $11.00, \mathrm{p}<.001$ ) indicating correlations for all pairs of latent factors were significantly different from 1.0.

\section{Multiple Indicators and Multiple Causes (MIMIC) Model}

We used MIMIC model to compare the means on the latent constructs of Attitude towards NASCAR, Corporate Reputation, Identification, Perceived CSR before and after the stimulus presentation. The MIMIC model specified two types of measured variables: (1) indicators of three latent emotion factors and (2) dummy- coded variables that differentiate among the three message groups. The number of dummy coded variable necessary for a MIMIC analysis was equal to the number of groups minus one. Therefore, we included one dummy-coded variables for each test. We coded dummy variables so the group in question was compared with all others. For example, we coded 1 for all individual in the En- 
vironmental (or Nationalistic) message group and 0 for all individuals in the other group. The model specified that the dummy-coded variable had direct effects on the four latent factors (see Figure 1).

\section{Table 1}

Psychometric Properties of Measures

\begin{tabular}{|c|c|c|c|c|}
\hline Constructs (Scale Sources): Items & $\lambda$ & S.E. & $\rho$ & AVE \\
\hline Attitude toward NASCAR & & & .84 & .63 \\
\hline NASCAR is favorable. & .66 & .06 & & \\
\hline NASCAR is valuable. & .85 & .04 & & \\
\hline NASCAR is attractive & .86 & .03 & & \\
\hline Corporate Reputation & & & .80 & .56 \\
\hline NASCAR has strong management. & .63 & .06 & & \\
\hline NASCAR uses high caliber advertisements. & .84 & .05 & & \\
\hline NAACAR sponsor many activities. & .77 & .05 & & \\
\hline Identification & & & .83 & .61 \\
\hline Being a fan of NASCAR is very important to me. & .79 & .05 & & \\
\hline How strongly do you see yourself as a fan of NASCAR? & .84 & .05 & & \\
\hline How strongly do your friends see you as a fan of NASCAR? & .72 & .07 & & \\
\hline Perceived CSR & & & .85 & .62 \\
\hline NASCAR participates in the management of public affairs. & .62 & .06 & & \\
\hline NASCAR allocates some of their resources to philanthropic activities. & .91 & .04 & & \\
\hline NASCAR plays a role in our society that goes beyond mere generation of profit. & .81 & .06 & & \\
\hline
\end{tabular}

The environmental model fit the data well $(\mathrm{S}-\mathrm{B} \chi 2 / d f=122.02 / 56=2.18, \mathrm{CFI}=.93, \mathrm{SRMR}=.05, \mathrm{RMSEA}=.09,90 \%$ $\left.\mathrm{CI}_{\text {RMSEA }}[.07, .11], \mathrm{WRMR}=.94\right)$. In addition, good psychometric properties demonstrated in the measurement model allowed for a straightforward interpretation of the four latent factors. As shown in Figure 1, the direct paths from the dummy-coded variable to Attitude toward NASCAR $(\gamma=.22 ; 95 \%$ CI $=.06, .38)$, Corporate Reputation $(\gamma=.17 ; 95 \%$ CI $=.01, .32)$, Identification $(\gamma=.22 ; 95 \% \mathrm{CI}=.05, .39)$, and Perceived CSR $(\gamma=.61 ; 95 \% \mathrm{CI}=.50, .73)$ were statistically significant in the expected direction. The significant path coefficients indicate that the population factor means of the emotion factors differ before and after the stimulus. Considering that the variables are standardized, the coefficient .61 for the path from environmental message to Perceived CSR refers to a $61 \%$ increase in Perceived CSR after watching the environmental promotion video. In addition, there were a 22\% increase in Attitude toward NASCAR, 17\% increase in Corporate Reputation, and 22\% increase in Identification under the environment message condition.

The nationalistic model fit the data well $(\mathrm{S}-\mathrm{B} \chi 2 / d f=101.86 / 56=1.81, \mathrm{CFI}=.93$, SRMR $=.07, \mathrm{RMSEA}=.09,90 \%$ $\left.\mathrm{CI}_{\text {RMSEA }}[.06, .11], \mathrm{WRMR}=.96\right)$. All the direct paths from the dummy-coded variable to the latent factors were not statistically significant (Attitude toward NASCAR: $\gamma=-.01,95 \%$ CI $=-.16, .16$; Corporate Reputation: $\gamma=-.08,95 \%$ CI $=-.29, .14$; Identification: $\gamma=.05,95 \%$ CI $=-.14, .25$; Perceived CSR: $\gamma=.32,95 \%$ CI $=-.03, .67)$. The standardized path coefficients of the latent constructs indicate a -1\% decrease in Attitude toward NASCAR, -8\% decrease in Corporate Reputation, and 5\% increase in Identification, and 32\% increase in Perceived CSR under the nationalistic message condition. 


\section{Figure 1}

\section{Research Framework}

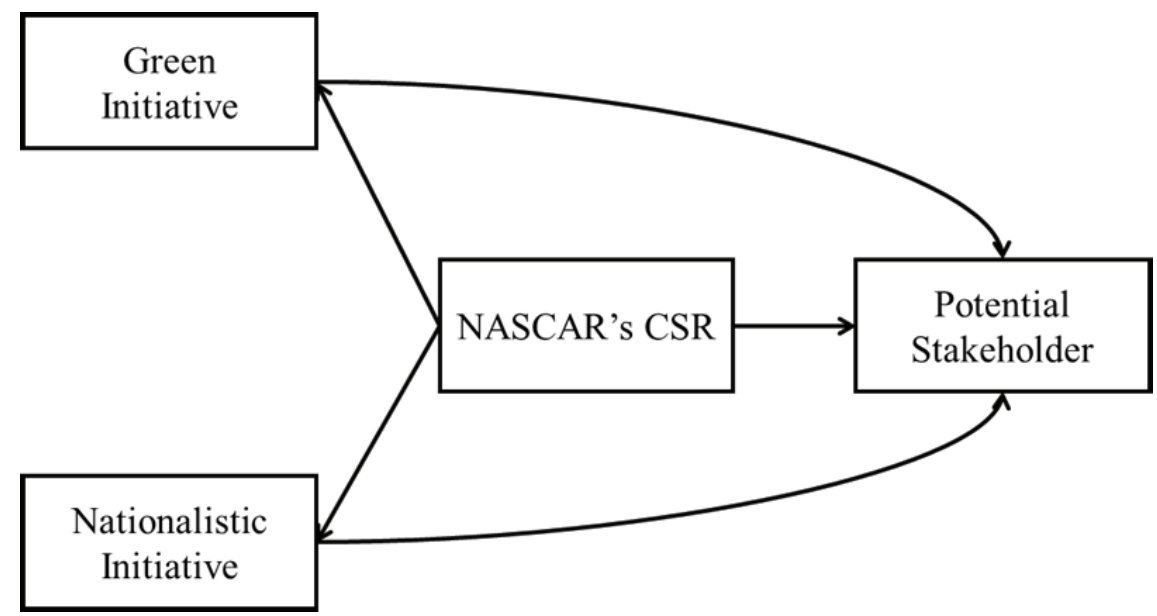

Figure 2

MIMIC model for positive and negative message

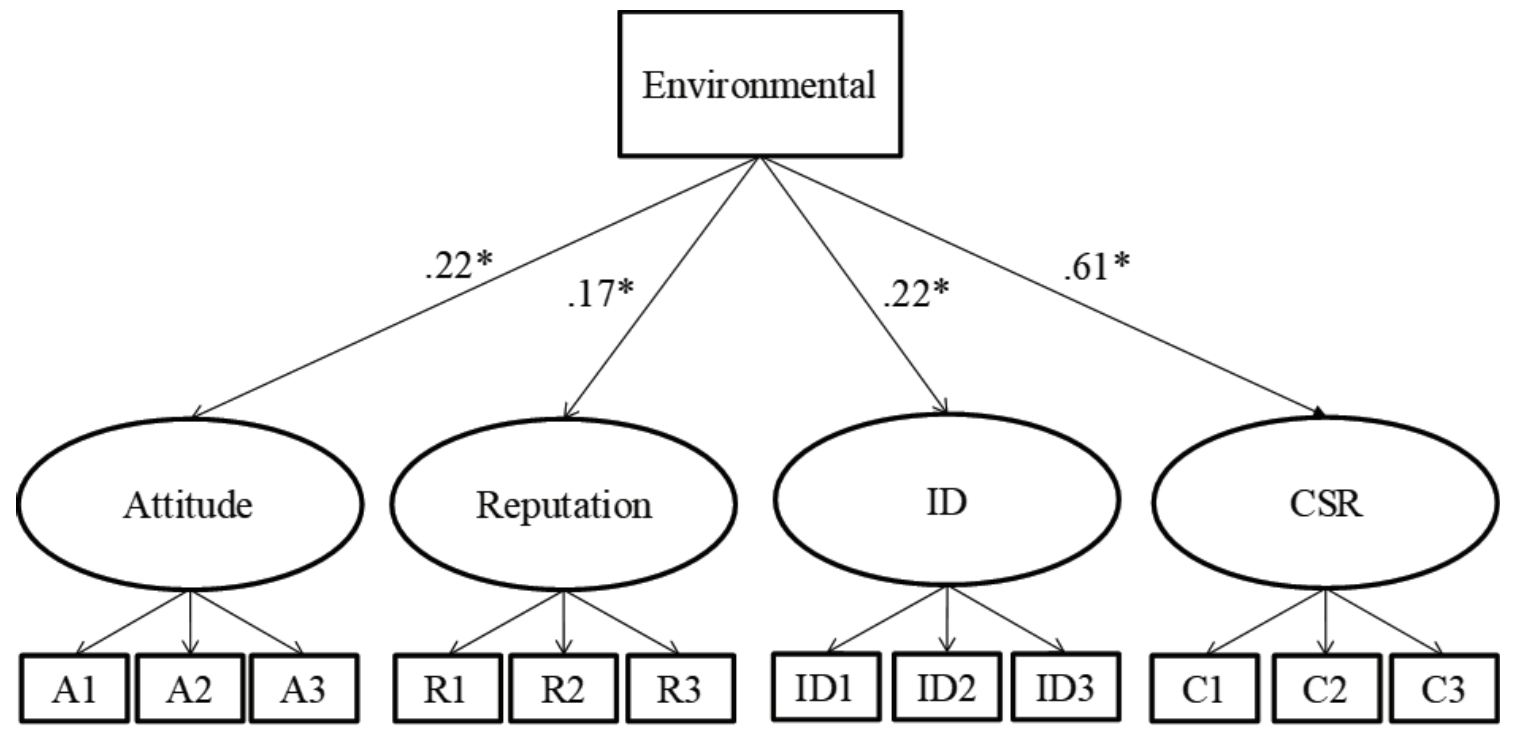

Note. ${ }^{*} p<.05$.

\section{Decriptive Analysis of RDAP}

We examined RDAP using a nominal variable on a scale of 1 - 4. A frequencies distribution was used to compare RDAP rating levels before and after the video viewing. For the environmental study, $69 \%$ of scores rated perceived social performance on the lower end of the scale (1-2), 30.7\% rated at a 3, no respondents rated at the highest level option before the viewing (Table 2). After viewing the environmental video, $22.7 \%$ of scores rated perceived social performance on the lower end of the scale (1-2), while $37.3 \%$ rated at a 3 and $40 \%$ rated at a 4 (Table 3 ). For the nationalistic study, $81 \%$ of scores rated perceived social performance on the lower end of the scale (1-2), while 18.3\% rated on the higher end of the scale (34) before the viewing. After viewing the nationalistic video, $50 \%$ of scores rated perceived social performance on the lower end of the scale (1-2), while 50\% rated on the higher end of the scale (3-4). Both approaches yielded significant changes. 
Figure 3

MIMIC model for nationalistic message

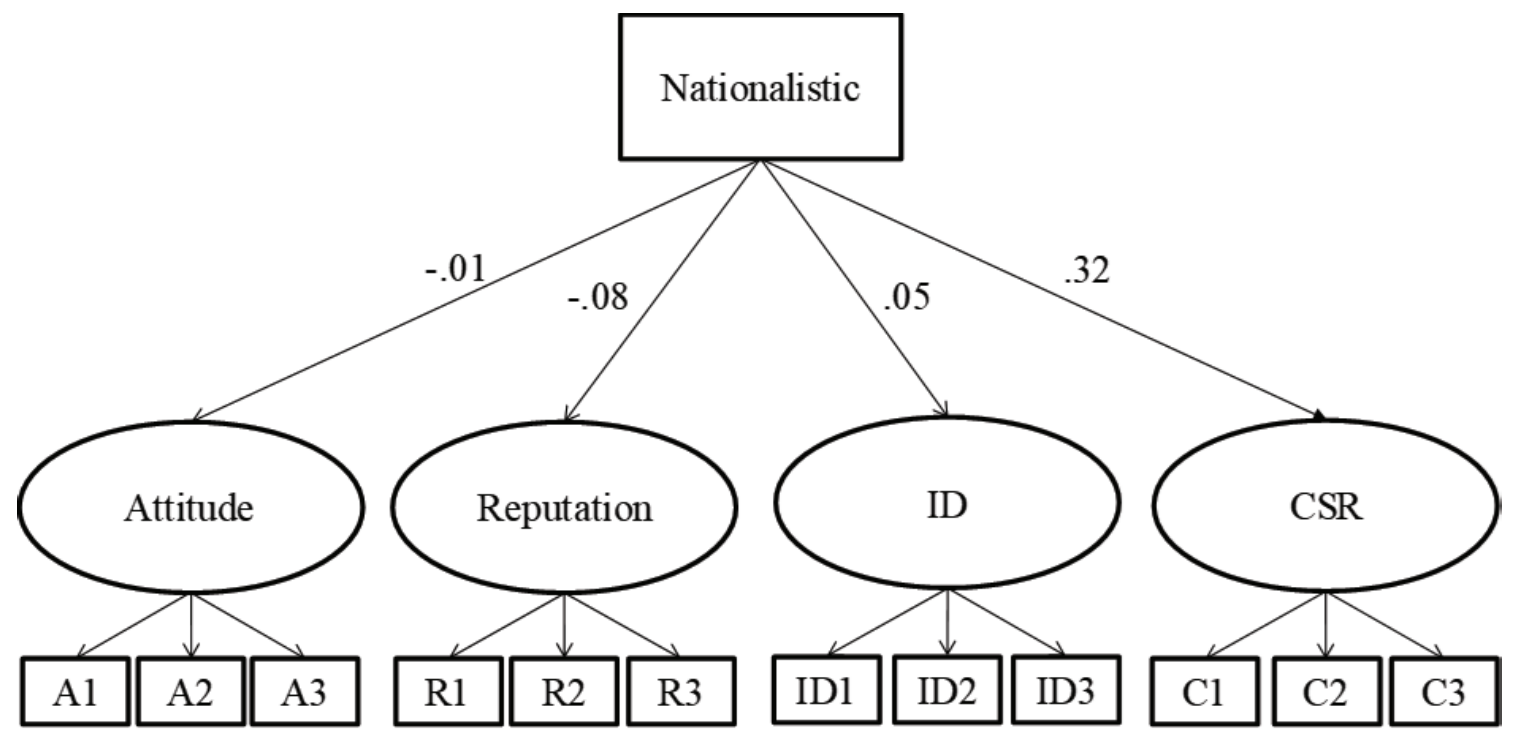

Note. ${ }^{*} p<.05$.

\section{Table 2}

RDAP Frequencies for Environmental Study

\begin{tabular}{lcccc}
\hline \multicolumn{1}{c}{ Scale } & Before & & & After \\
\hline Reactive & $n$ & $\%$ & 4 & 5.3 \\
Defensive & 26 & 34.7 & 13 & 17.3 \\
Accommodative & 26 & 34.7 & 28 & 37.3 \\
Progressive & 23 & 30.7 & 30 & 40.0 \\
\hline
\end{tabular}

Table 3

RDAP Frequencies for Nationalistic Study

\begin{tabular}{lcccc}
\hline \multicolumn{1}{c}{ Scale } & Before & & \multicolumn{2}{c}{ After } \\
\hline Reactive & $n$ & $\%$ & 7 & 11.7 \\
Defensive & 24 & 41.7 & 23 & 38.3 \\
Accommodative & 25 & 15.0 & 22 & 36.7 \\
Progressive & 9 & 3.3 & 8 & 13.3 \\
\hline
\end{tabular}




\section{Discussion}

The purpose of this research was to examine how potential stakeholders perceive the ways in which NASCAR communicates its CSR to address different stakeholder concerns. Through an experimental study, we examined the shift of attitudes and behaviors in potential stakeholders after their exposure to NASCAR's recent CSR efforts communicated as "nationalistic" or "environmental." The results of this research provide meaningful implications that further our knowledge of CSR and strategic cause-related marketing practices as potentially powerful sources of organizational reputation building. The findings suggest that CSR can be an opportunity for organizations like NASCAR to have a positive non-product message for potential stakeholders depending on how they communicate these programs.

Instead of being perceived as "green-washing" or defensive, like other companies such as British Petroleum (BP), NASCAR's environmental CSR was well received by participants. The communication of NASCAR's CSR as environmentally-concerned positively influenced corporate reputation, fan identification, attitude, and perceived CSR in potential stakeholders. These findings support previous research that has underscored the extent to which attitudes about organizational CSR initiatives impacted consumers' company evaluations positively and consumer behavior (Walker \& Kent, 2009; Brown \& Dacin, 1997; Kim, Kwak, \& Kim, 2010).

Although NASCAR's environmentally conscious CSR had a positive effect on all variables, the other CSR initiative communicated as "nationalistic" did not have a significant increase in any of the factors. The perceived CSR performance for the nationalistic message had the highest increase among all four factors but the effect was not significant. Of the remaining three factors, two, attitude and fan identification decreased. This result concurs with the research of Palihawadana, Oghazi, and Liu (2016). They suggest that consumers' ideological perception of CSR influences consumer behavior. Consumers display negative behavior toward a corporation when consumers perceive a CSR promotes values that are not consistent with the consumers' values (Palihawadana, et al, 2016). Therefore, the negative effects indicate the participants did not view the nationalism as favorable. Another possible explanation is that NASCAR projects strong nationalistic image and impact of this image is already reflected in the consumers' evaluation of NASCAR. The nationalistic message did not strengthen the image but just confirmed the existing one. This rationale, given the history of NASCAR, may better explain why there was no change in potential stakeholders' belief toward the organization.

As seen in previous research, CSR initiatives can, under certain conditions, decrease consumers' purchase intentions towards a company (Sen \& Bhattacharya, 2001). Highly nationalistic marketing may be seen as alienating or unfavorable to globally-concerned stakeholders and affect their attitudes and intentions negatively. However, for nationalistic (domestic-concerned) stakeholders it would not be seen as alienating.

Although the "nationalistic" communication of NASCAR's CRM may have been effective for other NASCAR stakeholder populations who embrace patriotism and nationalism, it was not a good fit for the participants in this study. The sample for this study was located in a more liberal area with college students who may be less nationalistic than the traditional NASCAR audience. Results from Brammer and Pavelin's (2006) study demonstrated the need to achieve a fit among the types of CSR and the company's stakeholder environment. Previous research has found that perceived consumer fit influences consumer perception of CSR activity and consequently on consumer-company identification and consumer loyalty (Lee, Park, Rapert, \& Newman, 2011).

These findings underscore marketers' need to adopt a strategic perspective in making CSR decisions. It is important for companies like NASCAR to align their CSR initiatives with not only the company's strategic marketing plan but also the positions of their desired stakeholder groups on CSR issues. In today's global society, promoting world issues like the environment can be beneficial for companies trying to attract a wider audience.

\section{Managerial Implications}

This study's findings provide a number of significant implications for managers. First, when performing and designing CSR initiatives, managers need to have a clear understanding of the STP (Segmenting, Targeting, and Positioning). STP is a very basic concept but still the most important one, which provides a framework for building marketing and promotional strategies (Mullin, Hardy, \& Sutton, 2014). The result of this study confirms the importance of selecting the right target audience and how a corporation should position itself toward the target audience.

In this study, the potential stakeholder perception of NASCAR's CSR and how it affected potential stakeholder behavior was tested. "Non-fans" or potential stakeholders clearly demonstrated that the messages played a part in shaping their 
perception of the company and, indeed, affected their willingness to become fans. Should a business such as NASCAR wish to expand its customer base, it is important to investigate the potential target groups' opinions about its image and representative values. For companies that aspire to grow beyond a local or regional market, managers should pay attention to stakeholder research and management. With NASCAR's nationalistic CSR messages, the organization was trying to change consumer beliefs and perceptions of the company. Such maneuvers may work with its existing clientele base. However, the negative effects of nationalistic messages indicate NASCAR needs to re-think its CSR strategies if NASCAR wants to expand its market.

The positioning of a company is the most important element in achieving success in any CSR activities. Correct positioning for the target audience (be they fans or non-fans) will contribute positively towards a company's target audience consumer behavior. In our study, NASCAR's two different positions, Environmental approach and the Nationalistic approach, elicited quite dissimilar responses from non-fans. The Nationalistic approach did not change consumer behavior for these potential customers whereas the Environmental approach had a positive influence. It is possible that non-fans initially viewed the organization as one of the most selfish organizations that burn fossil fuels and rubber tires for entertainment. Yet, they reconsidered the NASCAR brand with regard to the environment as evidenced by positive changes in Attitude, Reputation, Identification, and Perceived CSR activity after they were exposed to NASCAR's Environmental approach. In other words, this approach convinced potential stakeholders to change their belief about the organization that they believe to be a contributor to increased emissions and pollution.

On the contrary, poor or improper positioning may lead to inefficient use of resources when conducting CSR initiatives. Consider how NASCAR's Nationalistic approach was statistically insignificant in affecting non-fans' Attitude, Reputation, Identification, and Perceived CSR. Thus, it seems that NASCAR would be wasting its resources using this approach if it were to pursue a target audience beyond its traditional base.

A primary insight gleaned from existing CSR research suggests not all CSR activities are about fulfilling social responsibility (Malik, 2015). Often, a company's CSR initiatives have more to do with improving brand image than making a contribution to society. Why should managers monitor carefully their CSR programs which should be more than a reaction to bad publicities? Oscar Wilde (1890) famously noted, "There is only one thing in the world worse than being talked about, and that is not being talked about" (The Picture of Dorian Gray, p. 11). Similarly, the biggest PR myth of all, "There is no such thing as bad publicity", avows the same. If this is true, a company does not even need CSR to improve their image even as some may argue that bad publicity would yield a devastating result for a company (e.g., BP oil spills, Toyota recall, and Tiger Woods). A different perspective is offered here. Namely, the core meaning behind "there is no such thing as bad publicity" is the thought that while it puts negative energy toward the organization, it also gives it a unique chance to be in the spotlight, respond well to the negativity, and come back stronger for it.

All corporations have a responsibility to contribute to society. Due to the easy accessibility of information in contemporary society, many consumers believe that corporations should not be profitable while causing harm to society. When mistakes are made or greenwashing gets discovered, once loyal consumers may reject the goods or services of the offending corporations. To perform more effective CSR activities, organizations need to be careful in choosing their marketing messages. Perhaps most importantly from this study, corporations need CSR programs to demonstrate to the outside world that they are a positive force in society. If they put a sincere effort in their CSR programs, they will maintain their existing customer base and potentially cultivate new clientele.

\section{Limitations and Future Research}

This study had limitations that should be considered for future research. First, the sample used for this study was relatively small. Also, all of the participants were undergraduate college students in a small, college town in the Pacific Northwest. This might limit the external validity of the research findings. However, except for the age range, the sample coincides with NASCAR demographics of predominantly white males with some level of college education. This study was also interested in examining the levels of self-identified environmental consciousness and nationalism, yet was unable to do so. To improve the external validity of the findings, future research needs to use broader and wider samples (e.g., Southern populations, Eastern populations, primary stakeholders, non-students, and older age groups). It may also be interesting to examine how the different communications of CRM influence NASCAR's primary stakeholder groups, groups that identify as highly nationalistic, and groups that identify as highly environmentally conscious. 


\section{References}

Akhter, S. (2007). Globalization, expectations model of economic nationalism, and consumer behavior. Journal of Consumer Marketing, 24, 142-150.

Babiak, K., \& Trendafilova, S. (2011). CSR and environmental responsibility: Motives and pressures to adopt green management practices. Corporate Social Responsibility and Environmental Management, 18(1): 11-24. DOI: 10.1002/csr.229.

Bonifant, B. C., Arnold, M. B., \& Long, F. J. (1995). Gaining competitive advantage through environmental investments. Long Range Planning, 28, 128.

Brammer, S. J., \& Pavelin, S. (2006). Corporate reputation and social performance: The importance of fit. Journal of Management Studies, 43, 435-455.

Carroll, A. (1979). A three-dimensional conceptual model of corporate social performance. Academy of Management Review, 4, 479-505.

Clarkson, M. B. E. (1995). A stakeholder framework for analyzing and evaluating corporate social performance. Academy of Management Review, 20, 92-117.

Eitzen, D. S. (2012). Sport in contemporary society. New York: Oxford University Press.

Godfrey, P. C. (2009). Corporate social responsibility in sport: An overview and key issues. Journal of Sport Management, 23, 698-716.

Kim, K. T., Kwak, D. H., \& Kim, Y. K. (2010). The impact of cause-related marketing (CRM) in spectator sport. Journal of Management \& Organization, 16, 515-527.

Lee, E. M., Park, S. Y., Rapert, M. I., \& Newman, C. L. (2011). Does perceived consumer fit matter in corporate social responsibility issues? Journal of Business Research, 65, 1558-1564.

Malik, M. (2015). Value-enhancing capabilities of CSR: A brief review of contemporary literature. Journal of Business Ethics, 127, 419-438.

Maignan, I., \& Ferrell, O. C. (2004). Corporate social responsibility and marketing: an integrative framework. Journal of the Academy of Marketing Science, 32, 3-19.

Miles, M. P., \& Covin, J. G. (2000). Environmental marketing: A source of reputational, competitive, and financial advantage. Journal of Business Ethics, 23, 299-311.

Miller, T. (2017). Greenwashing sport. NY: Routledge.

Mosher, S.W. (2020, July 25). Nike should quit lecturing on social justice - and atone for using slave labor in China. The New York Post. Retrieved from https://nypost.com/2020/07/25/nike-should-quit-lecturing-on-social-justice-andatone-for-using-slave-labor-in-china/

Mullin, B. J., Hardy, S., \& Sutton, W. (2014). Sport Marketing 4th Edition. Champaign, IL: Human Kinetics.

Palihawadana, D., Oghazi, P., \& Liu, Y. (2016). Effects of ethical ideologies and perceptions of CSR on consumer behavior. Journal of Business Research, 69, 4964-4969.

Polonsky, M.J., \& Rosenberger, P.J. (2001). Re-evaluating to green marketing: An integrated approach. Business Horizons, 44, 21-30.

Sen, S., \& Bhattacharya, C. B. (2001). Does doing good always lead to doing better? Consumer reactions to corporate social responsibility. Journal of marketing Research, 225-243.

Stearns, J. M., Borna, S., \& Oakenfull, G. (2003). Buying for love of country: Assessing the ethics of patriotic appeals in advertising. Business and Society Review, 108, 509-521.

Trail, G., \& Mccullough, B. (2018). Differential Effects of Internal and External Constraints on Sustainability Intentions: A Hierarchical Regression Analysis of Running Event Participants by Market Segment. Journal Of Management For Global Sustainability, 6(2). doi:http://dx.doi.org/10.13185/JM2018.06206

Wartick, S. L., \& Cochran, P. L. (1985). The evolution of the corporate social performance model. Academy of Management Review, 10, 758-769. 